\section{Commentary: Robotic approach to mitral annular calcification-Are we doing more with less, or is less still more?}

\author{
Vinay Badhwar, MD
}

Video clip is available online.

In the current issue of the Journal, Loulmet and Grossi ${ }^{1}$ report their experience of patients with severe mitral annular calcification (MAC) and primary degenerative mitral regurgitation who underwent attempted isolated robotic mitral valve (MV) repair between 2011 and 2017. Their important contribution can be summarized by noting the significance of posterior mitral leaflet pliability as a determinant of successful robotic repair and the importance of a 2-surgeon team with advanced experience for optimal outcomes. Their innovative robotic application of Carpentier's en bloc resection technique ${ }^{2}$ is most laudable, as they took on 64 complex patients, 57 of whom had a successful outcome.

The mechanism of MAC is multifactorial, and its presence is seen in as many as $20 \%$ of patients undergoing MV surgery. ${ }^{3,4}$ Robotic MV repair has been shown to be durable and cost neutral to sternotomy, with excellent 1 -year outcomes in an all-comers approach, including patients with MAC. ${ }^{5}$ Once the learning curve of robotic MV repair surgery has been crested, and the operative team is duly experienced, many advanced centers now regularly apply robotic techniques to essentially all pathoanatomic presentations. 1,5

The management of MAC and concomitant severe MV disease has evolved to include complex repair and conventional MV replacement with or without annular

\footnotetext{
From the Department of Cardiovascular and Thoracic Surgery, West Virginia University, Morgantown, WVa.

Disclosures: Author has nothing to disclose with regard to commercial support.

Received for publication Jan 12, 2020; revisions received Jan 12, 2020; accepted for publication Jan 14, 2020; available ahead of print Feb 19, 2020.

Address for reprints: Vinay Badhwar, MD, Department of Cardiovascular \& Thoracic Surgery, West Virginia University, 1 Medical Center Dr, Morgantown, WV 26506-

8059 (E-mail: vinay.badhwar@wvumedicine.org).

J Thorac Cardiovasc Surg 2021;161:89-90

$0022-5223 / \$ 36.00$

Copyright (c) 2020 by The American Association for Thoracic Surgery

https://doi.org/10.1016/j.jtcvs.2020.01.088
}

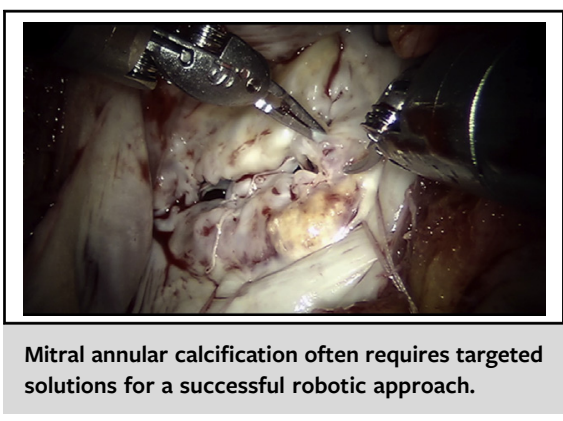

CENTRAL MESSAGE

Approaching mitral annular

calcification robotically requires

significant open surgical experi-

ence, with alternative strategies

to ensure patient safety and a

durable outcome.

reconstruction, percutaneous transcatheter MV replacement, and hybrid operations that may include open valvein-MAC off-label placement of an inverted transcatheter aortic valve device., ${ }^{4,6}$ Because of MAC's anatomic complexity, however, its variations in depth and severity, and the inherent risks to adjacent structures and atrioventricular continuity when intervened on, no technique has demonstrated marked superiority to another for this vexing problem. Loulmet and Grossi ${ }^{1}$ note correctly that advanced experience is important for successful robotic approach to MAC. This recommendation should be further clarified, however, to note that surgeons should have significant open sternotomy experience with MAC reconstruction before embarking on these techniques in a minimally invasive or robotic fashion.

The current experience of Loulmet and Grossi, ${ }^{1}$ although impressive, pertains essentially to a radical en bloc approach that used electrocautery complete resection, often requiring annular reconstruction with either primary atrioplasty or patch, as advocated by Carpentier more than 30 years ago. ${ }^{2}$ In the open approach, this en bloc technique has been associated with an operative mortality of $9 \%$ and early repair failure of $11 \%$, even in experienced hands. ${ }^{7-9}$ Although the experience of Loulmet and Grossi ${ }^{1}$ of 2 operative mortalities, 2 operative conversions, and 3 acute failures requiring reoperation before discharge may be interpreted as slightly better than historical reports, one must question whether the en bloc technique is the only 


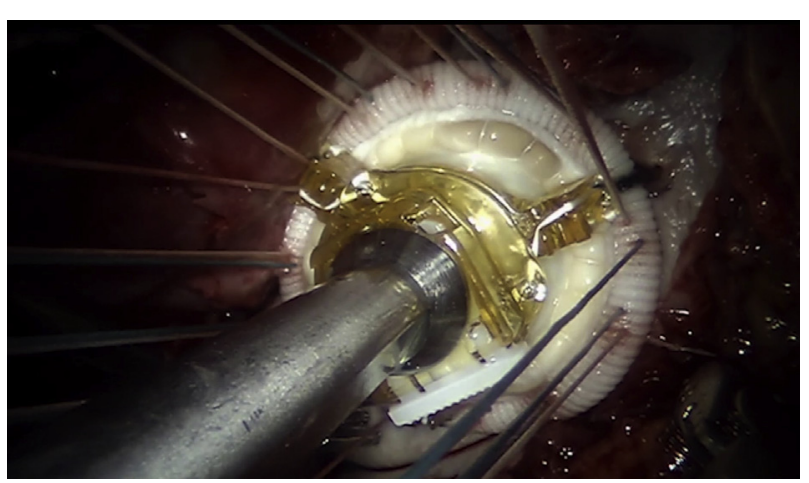

VIDEO 1. A 64-year-old woman on home oxygen therapy with severe regurgitation and stenosis secondary to mitral annular calcification was turned down for conventional surgery and transcatheter mitral replacement after heart team assessment. The patient was discharged home on the seventh postoperative day after a targeted robotic approach to her mitral calcification. Video available at: https://www.jtcvs.org/article/S0022-5223(20) 30443-8/fulltext.

way to navigate MAC and yet obtain a successful patient outcome.

Given the variations of the depth and degree of impingement of the posterior mitral leaflet, a selective and less radical resection of MAC has been a successful and less morbid alternative. ${ }^{10} \mathrm{~A}$ targeted and segmental approach to regions that most impair leaflet mobility in less severe MAC can be quite successful in safe MV repair. In patients with advanced age, focal resection of MAC can facilitate successful MV repair or replacement. In patients otherwise at high risk for sternotomy, segmental annular resection and debulking the MAC, perhaps by using the anterior mitral leaflet as a patch, may afford a simplified pathway to secure annular sutures and a well-seated MV prosthesis performed robotically (Video 1).
Preoperative planning with transesophageal echocardiography and computed tomographic imaging is essential to ensure the necessary preparedness when approaching patients with severe MAC. Although the approach to MAC and MV surgery can indeed be performed with less invasive means, with an ability to do even more robotically, when approaching patients with advanced disease, we must focus on a safe and effective outcome, perhaps with more targeted resection. Thus for MAC, sometimes less is still more.

\section{References}

1. Loulmet DF, Ranganath NK, Neragi-Miandoab S, Koeckert MS, Galloway AC, Grossi EA. Advanced experience allows robotic mitral valve repair in the presence of extensive mitral annular calcification. J Thorac Cardiovasc Surg. 2021;161:80-8.

2. Carpentier AF, Pellerin M, Fuzellier JF, Relland JY. Extensive calcification of the mitral valve anulus: pathology and surgical management. J Thorac Cardiovasc Surg. 1996;111:718-29; discussion 729-730.

3. Abramowitz Y, Jilaihawi H, Chakravarty T, Mack MJ, Makkar RR. Mitral annulus calcification. J Am Coll Cardiol. 2015;66:1934-41.

4. Bedeir K, Kaneko T, Aranki S. Current and evolving strategies in the management of severe mitral annular calcification. J Thorac Cardiovasc Surg. 2019; 157:555-66.

5. Coyan G, Wei LM, Althouse A, Roberts HG, Schauble D, Murashita T, et al. Robotic mitral valve operations by experienced surgeons are cost-neutral and durable at 1-year. J Thorac Cardiovasc Surg. 2018;156:1040-7.

6. Sorajja P, Gössl M, Babaliaros V, Rizik D, Conradi L, Bae R, et al. Novel transcatheter mitral valve prosthesis for patients with severe mitral annular calcification. J Am Coll Cardiol. 2019;74:1431-40.

7. Cammack PL, Edie RN, Edmunds LH Jr. Bar calcification of the mitral anulus. A risk factor in mitral valve operations. J Thorac Cardiovasc Surg. 1987;94: 399-404.

8. Feindel CM, Tufail Z, David TE, Ivanov J, Armstrong S. Mitral valve surgery in patients with extensive calcification of the mitral annulus. J Thorac Cardiovasc Surg. 2003; 126:777-82.

9. Tomšič A, Hiemstra YL, van Brakel TJ, Versteegh MIM, Marsan NA, Klautz RJM, et al. Outcomes of valve repair for degenerative disease in patients with mitral annular calcification. Ann Thorac Surg. 2019;107: 1195-201.

10. Carrel TP, Weber A. Selective, segmental decalcification: a safe alternative to extensive debridement of a severely calcified annulus during repair of mitral regurgitation. Interact Cardiovasc Thorac Surg. 2016;23:665-7. 